\title{
Malignant Hypertension: Ocular Manifestations
}

\author{
Silvia Muñoz ${ }^{1,3, *}$, Nieves Martín ${ }^{2}$, and Jorge Arruga ${ }^{1,3}$ \\ ${ }^{1}$ Ophthalmology Department, Hospital Universitari Bellvitge, Barcelona, Spain; \\ ${ }^{2}$ Ophthalmology Department, Hospital Universitari Vall d'Hebró, Barcelona, Spain; \\ ${ }^{3}$ Ophthalmology Department, Hospital Universitari Sagrat Cor, Institut català de \\ Retina, Barcelona, Spain \\ E-mail: silviamq@teleline.es
}

Received January 3, 2006; Accepted January 5, 2006; Published January 26, 2006

\begin{abstract}
Malignant hypertension may be the first manifestation of systemic hypertension. We report a clinical case of a Caucasian 41-year-old man with no previous history of blood hypertension seen at casualty because of blurred vision. Fundus examination disclosed optic disk swelling, retinal hemorrhages and infarcts. The blood pressure was 220/130 $\mathrm{mmHg}$. After the appropriate management of hypertension, optic disk and retinal edema resolved, leaving minor changes as mild optic disk pallor and hard exudates.
\end{abstract}

KEYWORDS: Optic disk swelling, cotton-wool spots, malignant hypertension, hypertensive neuro-retinopathy
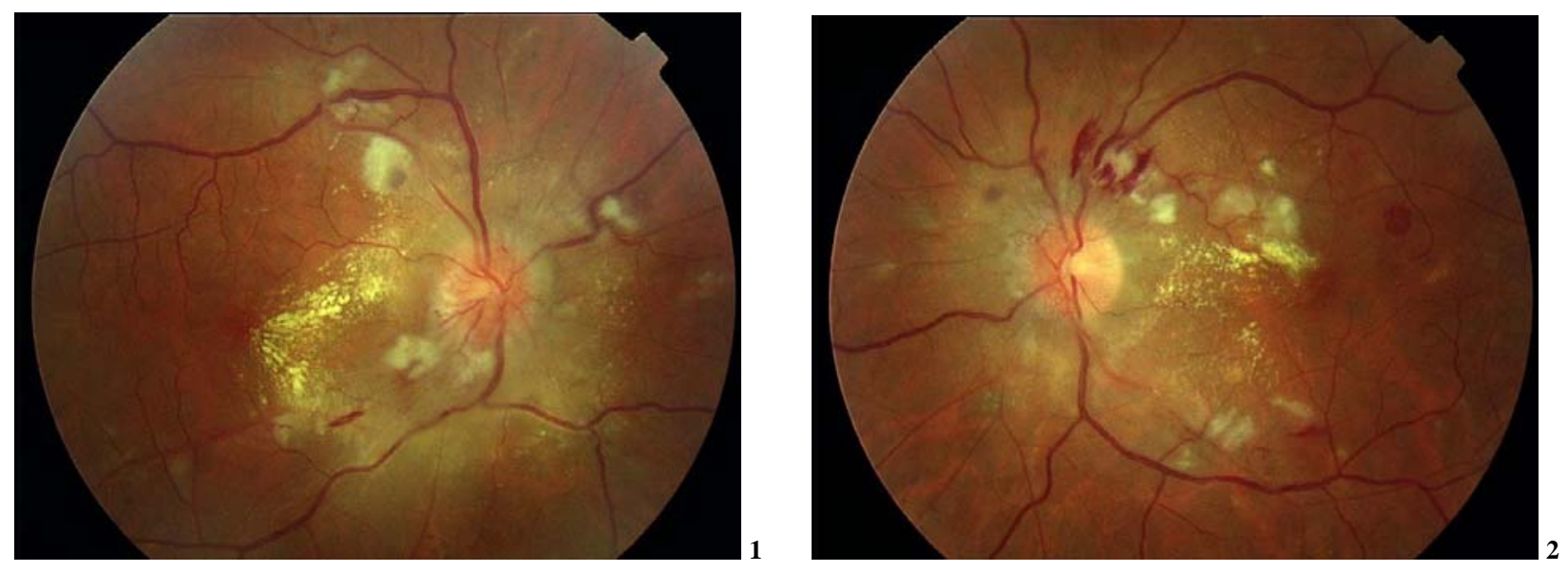

FIGURES 1 RE - 2 LE. Bilateral optic disk edema with prominent telangiectatic vessels on the surface of both optic disks. There are retinal microinfarcts (cotton-wool spots) and hard exudates in the macular area forming a macular star. 

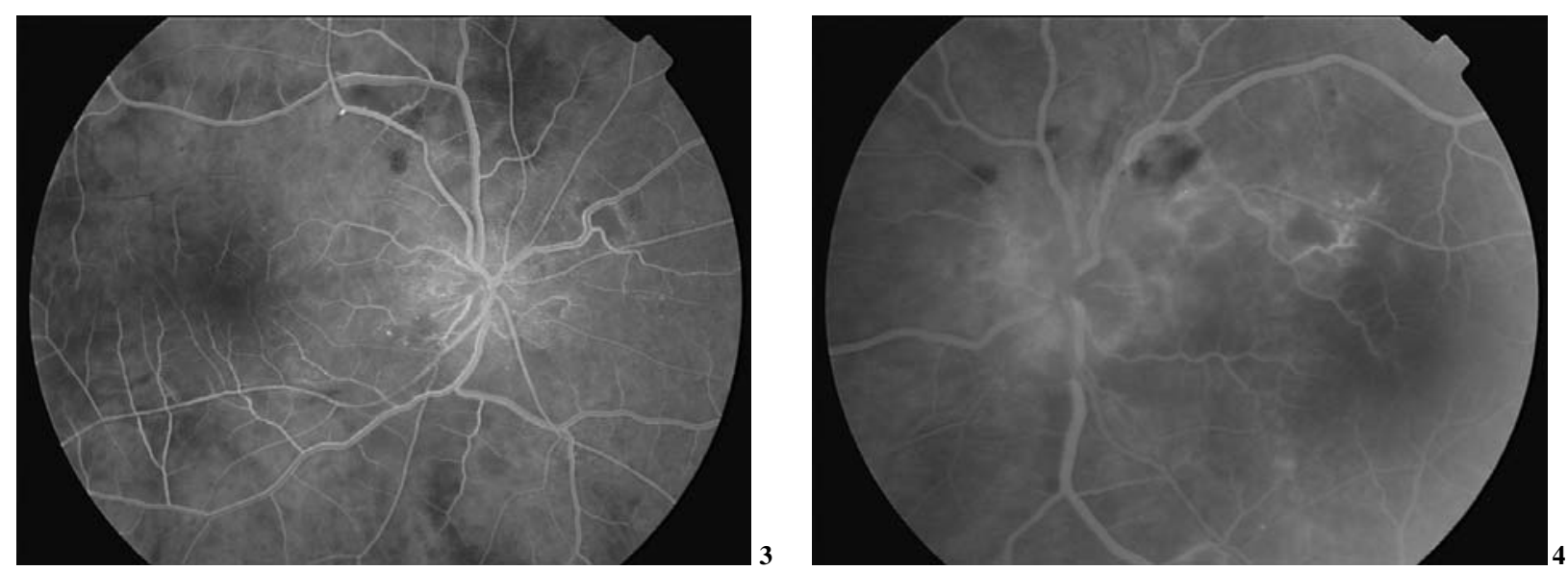

FIGURES 3 RE - 4 LE. Fluorescein angiogram showing an artery occlusion (RE superior temporal branch) and wide areas of choroidal ischemia in both eyes. Retinal haemorrhages are seen as black dots as they block normal fundus fluorescence.
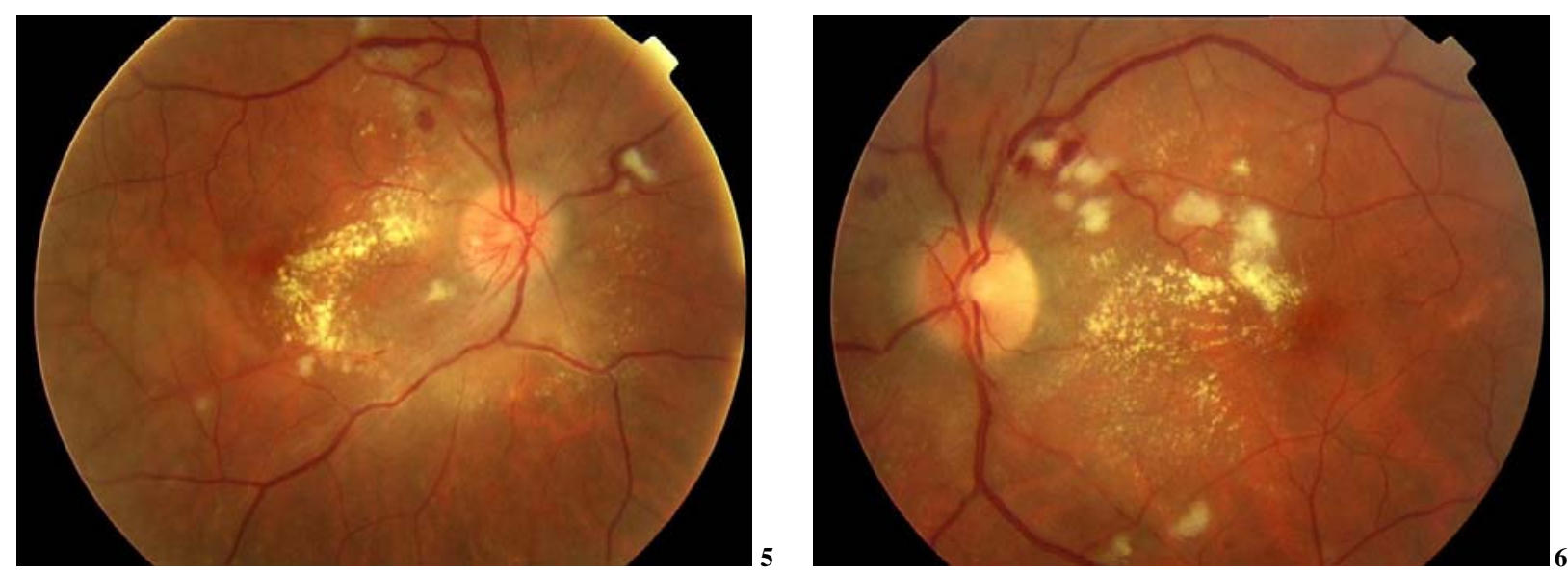

FIGURES 5 RE - 6 LE. Two months later, there is still optic disk swelling and lipid (hard) exudates.
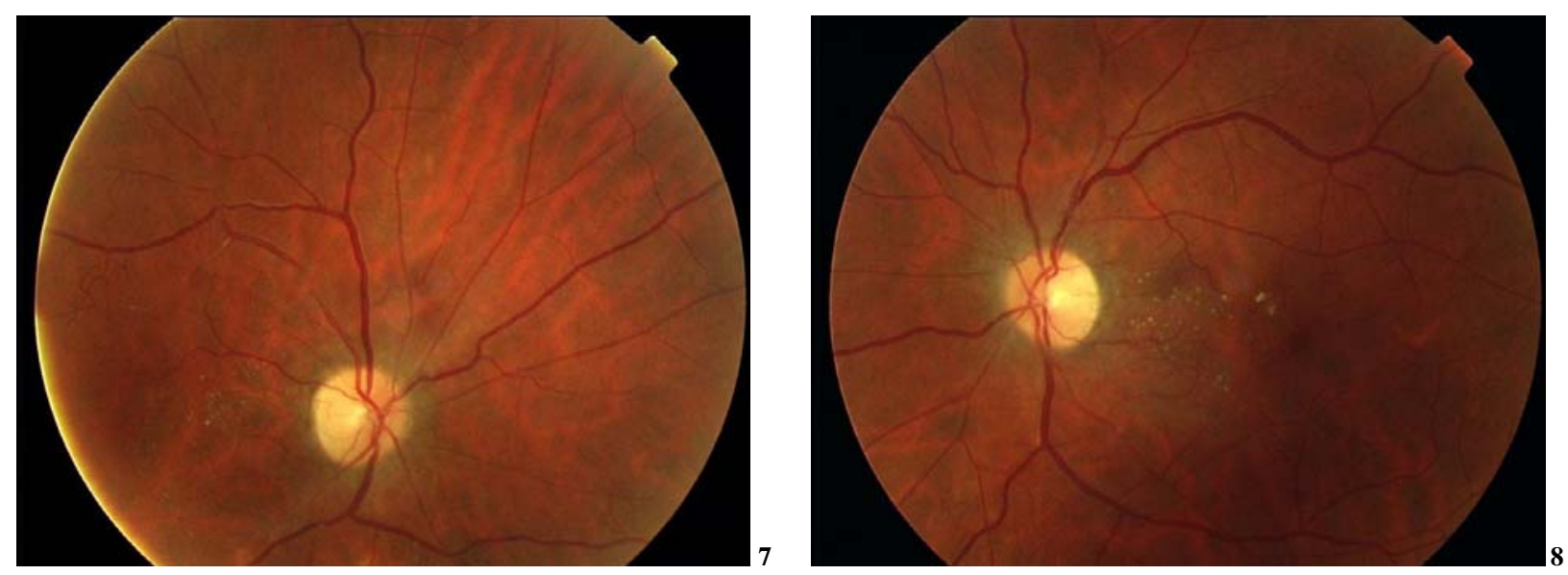

FIGURES 7 RE - 8 LE. Eight months after hypertension onset, temporal optic disk pallor is seen, as well as retinal arterial narrowing and lipid exudates. 


\section{REFERENCES}

- $\quad$ Hayreh, S.S., Servais, G.E., and Virdi, P.S. (1986) Fundus lesions in malignant hypertension. V. Hypertensive optic neuropathy. Ophthalmology, 93, 74-87.

- Hayreh, S.S. (1989) Classification of hypertensive fundus changes and their order of appearance. Ophthalmologica, 198, 247-60.

- $\quad$ Sapira, J.D. (1984) An internist looks at the fundus oculi. Dis Mon., 30, 1-64.

This article should be cited as follows:

Muñoz, S., Martín, N., Arruga, J. (2006) Malignant hypertension: ocular manifestations. TheScientificWorldJOURNAL 6, 122124. DOI 10.1100/tsw.2006.28. 


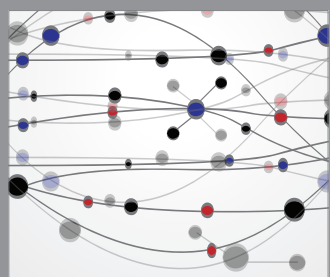

The Scientific World Journal
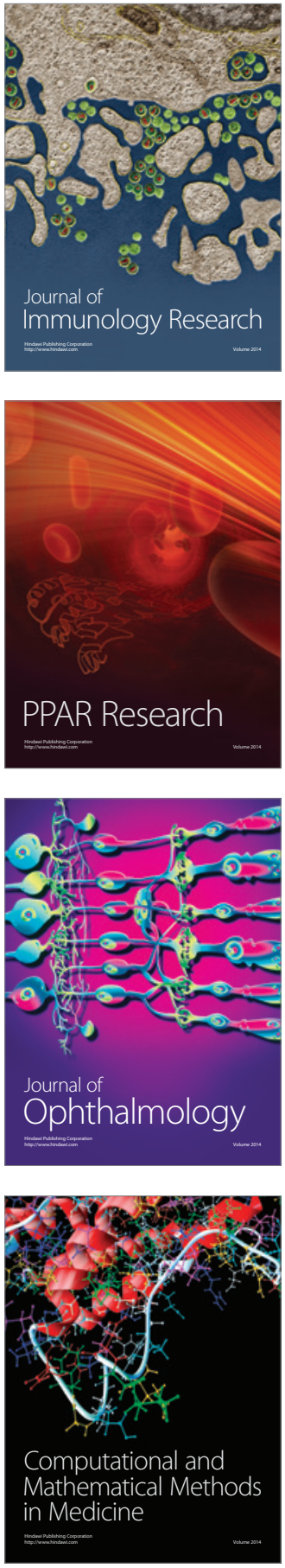

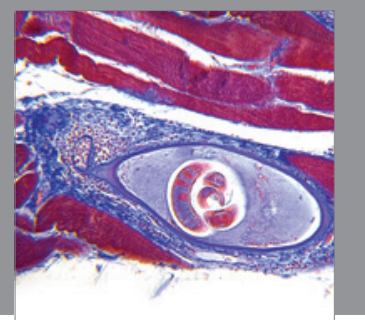

Gastroenterology

Research and Practice
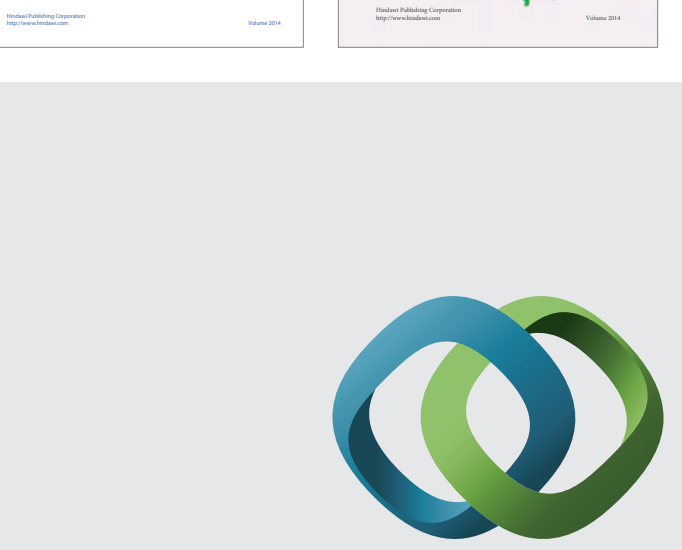

\section{Hindawi}

Submit your manuscripts at

http://www.hindawi.com
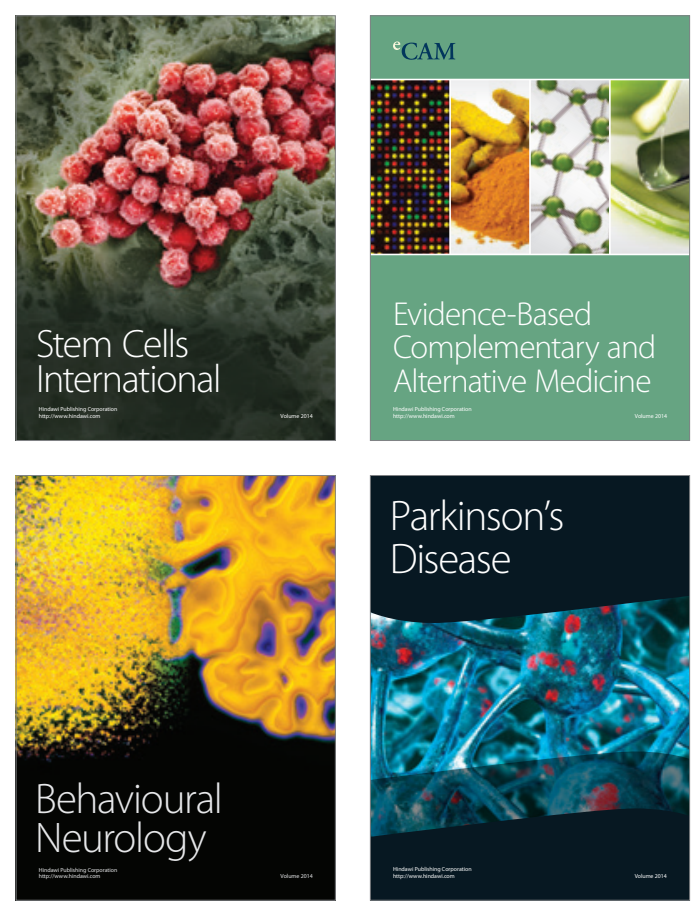

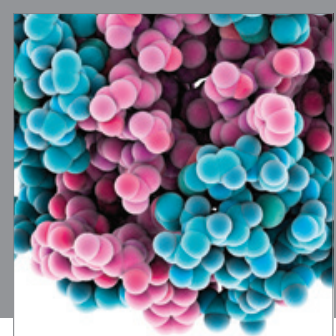

Journal of
Diabetes Research

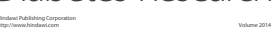

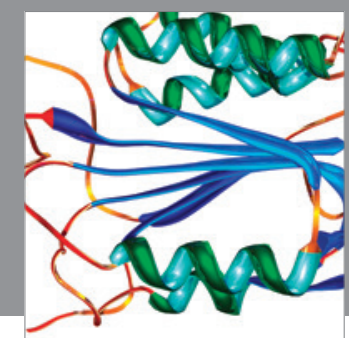

Disease Markers
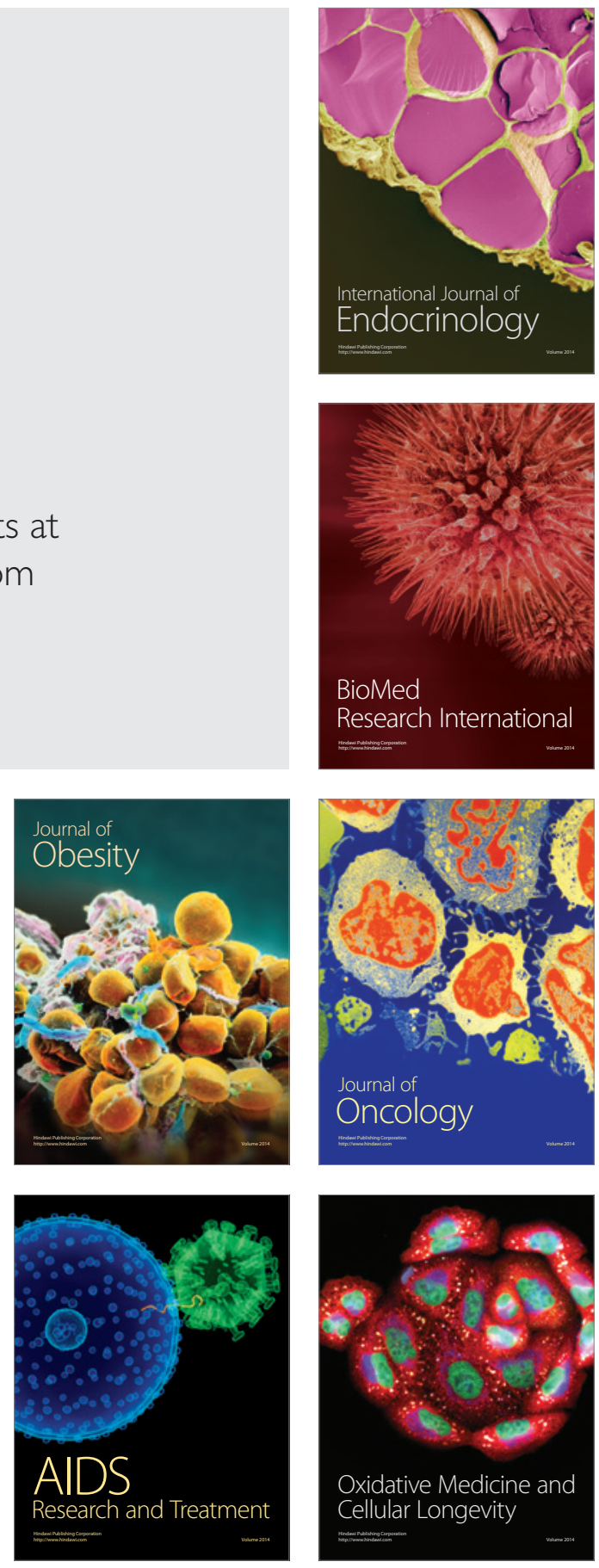